\title{
The Diagnosis of Fetal Sexing in Cattle Using Ultrasound
}

\author{
Liviu Marian BOGDAN ${ }^{1}$, Anamaria Blaga PETREAN ${ }^{1 *}$, Ioan Coman $^{3}$,George NADĂŞ ${ }^{1}$, Mihai CENARIU ${ }^{1}$, \\ Ileana BOGDAN ${ }^{2}$, Sidonia BOGDAN ${ }^{1}$, Daniel BEREAN ${ }^{1}$ \\ ${ }^{1}$ Faculty of Veterinary Medicine, University of Agricultural Sciences and Veterinary Medicine Cluj-Napoca, \\ Calea Mănăştur, no. 3-5, 400372, Romania, \\ ${ }^{2}$ Faculty of Agriculture, University of Agricultural Sciences and Veterinary Medicine Cluj-Napoca, Calea \\ Mănăștur, no. 3-5, 400372, Romania, \\ ${ }^{3}$ DSVSA Brasov, Romania \\ *corresponding author: anamaria.petrean@usamvcluj.ro
}

Bulletin UASVM Veterinary Medicine 76(2)/2019

Print ISSN 1843-5270; Electronic ISSN 1843-5378

doi:10.15835/buasvmcn-vm:2019.0008

\begin{abstract}
:
The purpose of this research was to conduct an ultrasound exam in the interval between 49-120 days of gestation for the determination of fetus sex and to establish the interval when the fetal sexing is possible. The research was carried out in three farms from Transylvania. In farm A were examined 25 animals, in farm B 13 animals and in farm C 11 animals. The diagnosis of the fetal sexing was possible for 35 cases, 14 animals were diagnosed as female and 21 were male. In the interval between 56-65 days of gestation the diagnosis of fetal sexing was established by viewing the genital tubercle and in the interval between 65-90 days of gestation the diagnosis was established by viewing the secondary genital organs. In 14 cases the diagnosis was not set; in 4 cases the conception product has not been sufficiently developed, the genital tubercle was not visible, and in 10 cases the fetus was too big and was impossible to localize the genital organs.
\end{abstract}

Keywords: cattle, diagnosis, fetal sexing, ultrasound.

\section{Introduction}

The economics of food animal production is the driving force behind advanced reproductive technologies in the cattle industry. For the past 15 years, the use of ultrasound has proven to be a valuable tool for cattle breeders to assess carcass characteristics and to provide valuable reproductive information beyond the scope of rectal palpation (Stroud, 2005). The literature on ultrasound use is in agreement that ultrasound examinations of the reproductive tract now offer practitioners one of the most rapid, precise, and cost-effective means of diagnosis in bovine reproductive medicine (Coteaux and Fetrow,
1998; Oltenacu et al., 1990; Coteaux and Buczinski, 2009). Determination of fetal sexing in cattle is of great importance, at least for the following reasons: pregnant cows and heifers carrying a female fetus have greater economic value, especially in dairy breeds; fetal sex may play an important role in selling pregnant heifers that have a high genetic quality; sexing allows detection of twin pregnancies consisting of a male and female fetus, which may lead to free martinism; knowledge of fetal sex may allow the breeder to decide whether to keep a pregnant cow for lactation or to cull it in time (Tainturier, 2001). 
Fetal sex determination can be a valuable tool on modern-day dairy farms (Tayler, 2011). Early fetal sex determination is generally carried out between days 55 and 65 of pregnancy. On day 55 the genital tubercle is located halfway between its initial and final positions, but by day 60 it has reached its final position, caudal to the umbilicus in the male fetus and just under the tail in the female fetus (Tyler, 2013). A study by Tainturier (2001) found that early fetal sex determination using ultrasonography is both accurate and safe. They concluded that the average success rate for 107 fetal sex diagnoses carried out between days 54 and 69 of pregnancy was 81\%, although the success rate for the more certain diagnoses was $92 \%$. They also found that success rate was significantly higher after day 60 of pregnancy when the genital tubercle has reached its final position. The abortion rate of the cows in the study was found to be $2 \%$, which corresponded to the expected abortion rate of cows at the time. It is important to remember that these rates will depend on the skill of the operator (Tainturier, 2001).

Late sexing is possible by identification of specific genital structures in males or females. The penis can be observed between days 80 and 100 as an echogenic line between the hind legs of males, while the scrotal pouches appear as two echogenic spots to the right and left of the penis. The scrotal pouches can also be observed in cross sections, like two swellings between the hind legs. In females, the structures that can be identified between days 80 and 100 are the mammary buds (four echogenic spots that sometimes may appear bilobar), the median raphe (an echogenic line between the hind legs) and the clitoris (the structure resulting from the genital tubercle, situated in direct contact with the tail) (Cenariu et al., 2012).

The purpose of this research was to conduct a transrectal ultrasound exam in the interval between 49-120 days of gestation in the aim to determinate the sex of the conception product and the interval when the fetal sexation is possible.

\section{Materials and methods}

The research has been carried out during January 2017-April 2017 in three cattle farms from Transylvania: in farm $A\left(F_{A}\right)$ were examined 25 animals, in farm $B\left(F_{B}\right)$ were examined 13 animals and in farm $\mathrm{C}(\mathrm{Fc})$ were observed 11 animals. All the animals that were in the interval between 49120 days of gestation were examined. For this study was utilized the ultrasound Easy Scan Linear in the fetal sexing mode accompanied with the BUG ultrasound goggles. The animals enclosed in study were from mixed breeds: Romanian Spotted breed and Fleckvieh.

Three views were used to observe a fetus during an ultrasound examination: a lateral view (seldom seen), a frontal view (routinely seen and easiest for orientation), and a cross-sectional view (the most often presented). Angled or oblique variations of these views are often presented during routine ultrasound exams (Stroud, 2005).

During a cross-sectional examination of the fetus, the transducer was placed over the cranium and moved distally through the thorax to review the beating heart. The transducer was moved further distally to where the umbilicus attaches to the abdomen. At this time, the transducer was moved slowly back and forth to diagnose the presence or absence of a male genital tubercle. In males, the genital tubercle was observed immediately caudal to the umbilicus, this appears very bright or highly echogenic on the monitor, with bilobate aspect. If a male genital tubercle was detected, the examination was finished. If a male genital tubercle was not observed, the transducer was moved distally to the perineal area to detect the presence of a female genital tubercle. The perineal area was the most difficult region of the fetus to focus, the transducer was moved slowly for view the female tubercle. It is important here to establish the difference between a cross-sectional view of the tail and the female genital tubercle. The female genital tubercle is generally bilobate, whereas the tail is a monolobate structure. Frequently, the tail and female genital tubercle are seen simultaneously and the ultrasonographer should definitively distinguish one structure from the other (Stroud, 2005).

When the fetus was in a frontal position, the head, thorax, abdomen, and inguinal area was viewed. The transducer was manipulated so that the umbilical attachment to the abdomen comes into focus. In males, immediately caudal to the umbilicus was seen the hyper echogenic male genital tubercle. The female genital tubercle was sometimes superimposed over the tail. The transducer was moved to the left or right, a slightly oblique angle was created and the two structures 
Table. 1. Diagnosis situation in each farm

\begin{tabular}{cccc}
\hline & $\mathbf{F}_{\mathbf{A}}$ & $\mathbf{F}_{\mathbf{B}}$ & $\mathbf{F}_{\mathbf{C}}$ \\
\hline Examined animals & 25 & 13 & 11 \\
\hline Male fetus & 11 & 5 & 5 \\
\hline Female fetus & 9 & 3 & 2 \\
\hline No diagnoses & 5 & 5 & 4 \\
\hline
\end{tabular}

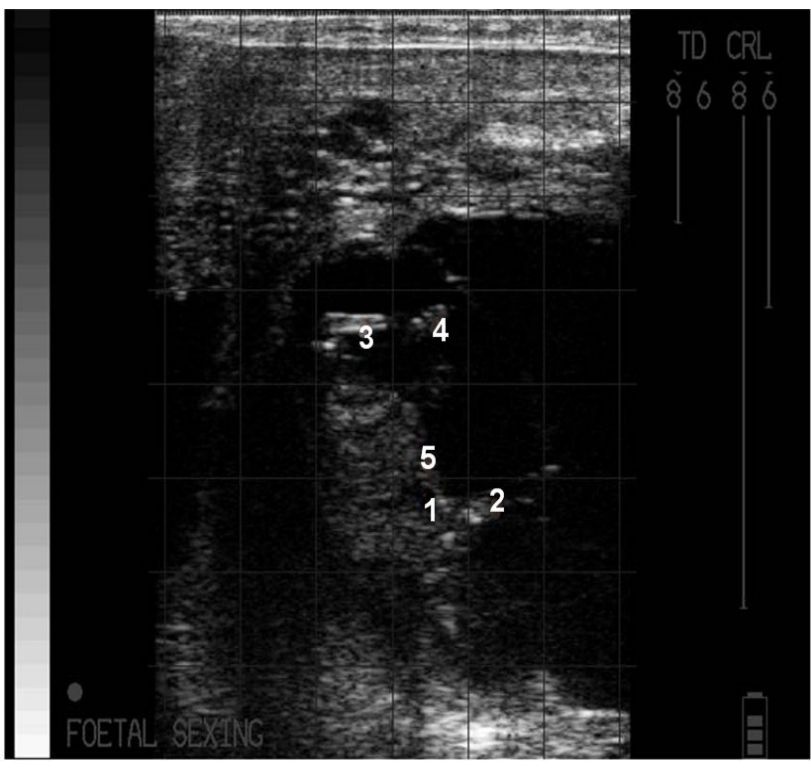

Figure 1. Gestation 56 days male fetus (lateral view) 1-male genital tubercle, 2-rear leg, 3-head, 4-frontal leg, 5-umbilicus

were effectively separated optically (Stroud, 2005).

Lateral-view orientation was presented occasionally, the female genital tubercle was somewhat difficult to visualize using this position and the assessor was constrained to change the angle.

\section{Results and discussion}

In this study were examined 49 pregnant animals with gestational age ranging from 49 days to 110 days of gestation. The diagnosis of the fetal sex was made for 35 cases, 14 animals were diagnosed as female fetus and 21 as male fetus. The results regarding the situation on each farm are presented in Table 1.

In 14 cases were not possible to diagnose the sex of the product due to gestational age, 4 of these cases were in an early gestation period, and 10 of them had a too late gestational age. In the interval between 45-55 days of gestation the

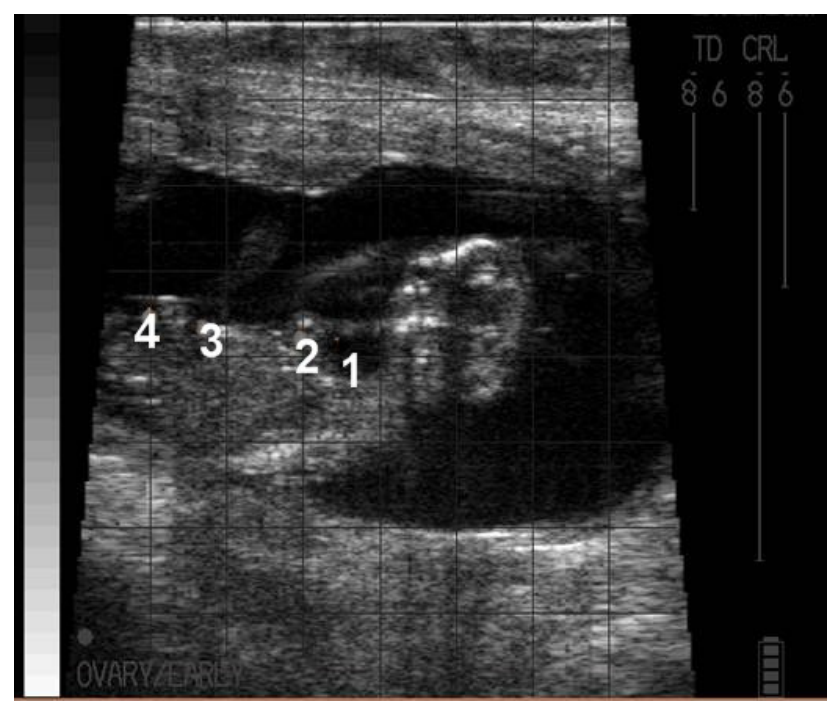

Figure 2. Gestation 62 days male fetus (oblique lateral view)

1-heart, 2-umbilicus, 3-male genital tubercle, 4-rear leg

diagnosis was not set because the genital tubercle was not visible, in some cases a structure with high echogenity was seen but the position of this structure was between the hind legs. After 90 days of gestation, 10 animals were examined, but the diagnosis of fetal sexing was not established, the robust constitution of the animals examined as well as the advanced age of these individuals led to the impossibility of fully viewing the product of conception and implicitly the impossibility of establishing a diagnosis of sex. In the interval between 55-65 days of gestation the diagnosis of fetal sexing was set by viewing the genital tubercle, a bilobate structure with high echogenity who was situated caudal of the umbilicus in the male fetus (Figure 1, Figure 2) and just under the tail in the female fetus (Figure 3 ).

In the interval between 65-90 days of gestation the diagnosis was established by viewing the secondary genital organs. In males, in this interval, was seen the scrotum between the rear legs like an echogenic structure, in some cases was 


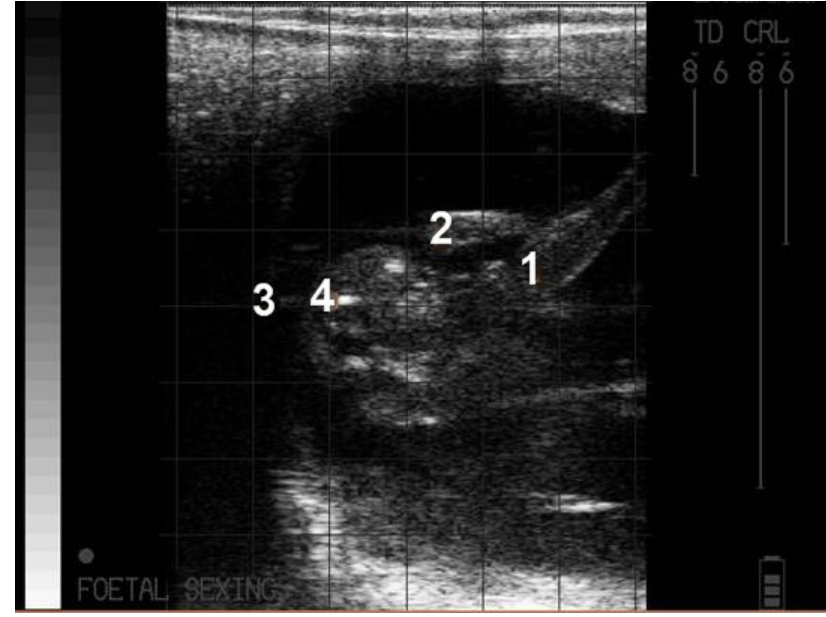

Figure 3. Gestation 63 days female fetus (cross section view)

1-front leg, 2-rear leg, 3-tail, 4-female genital tubercle

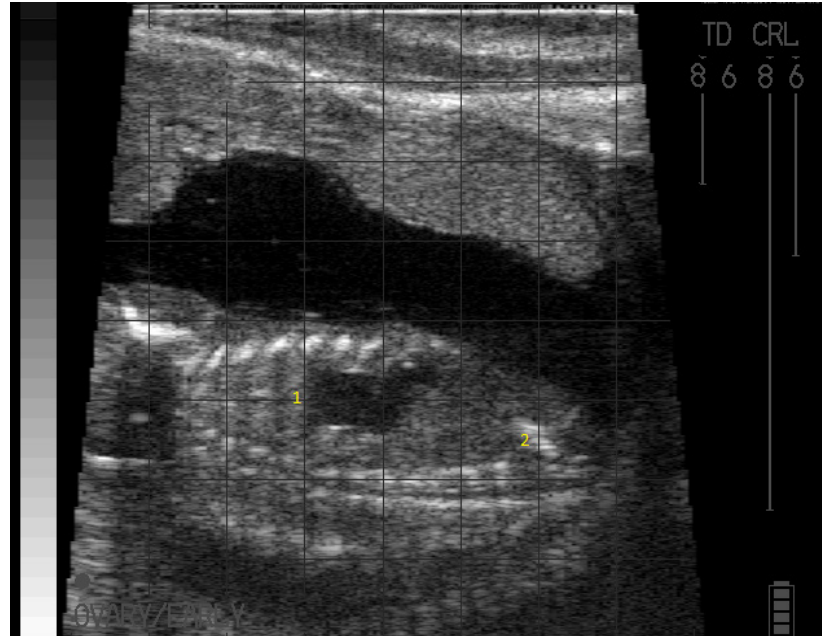

Figure 4. Gestation 82 days male fetus (oblique lateral view) 1-heart, 2-scrotum

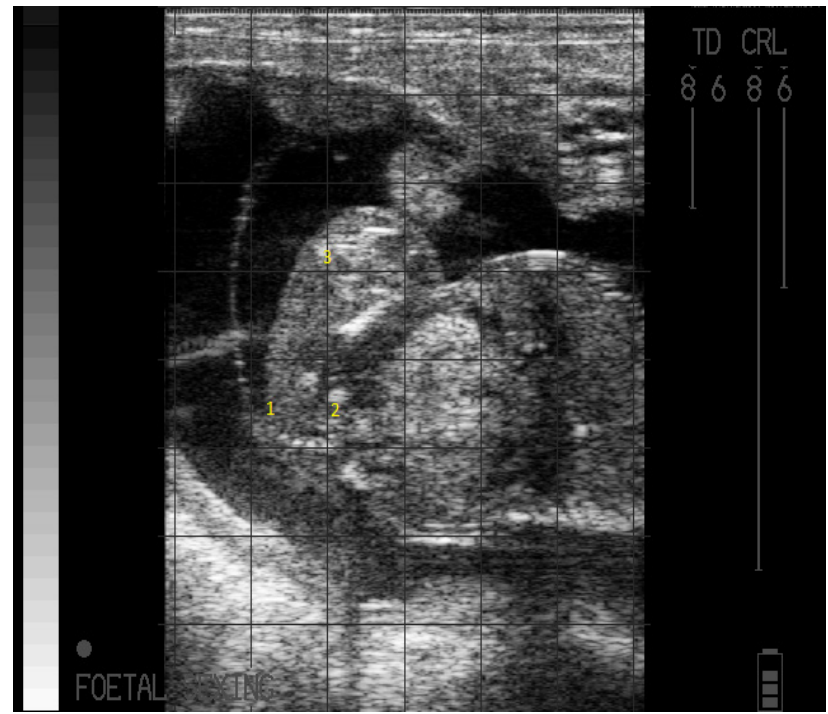

Figure 5. Gestation 75 days female fetus (oblique cross view)

1-tail 2-teats 3-rear leg

seen also the penis, another echogenic structure situated cranial of scrotum (Figure 4). In females, 4 echogenic structures were seen between the rear legs, this represent the teats (Figure 5).

In our study the specificity of method was $97 \%$ (only in one case the diagnosis was set incorrect). After 90 day of gestation the diagnosis was not established because the genital organs of fetus were not localized. The robust constitution of the mother and the migration of genital apparatus into abdominal cavity made impossible the diagnosis at this age of gestation. The results regarding the diagnosis on each period are presented in Table 2 .
Sex diagnosis based on the presence or absence of secondary reproductive structures is not advised, because inexperienced persons sometimes see hyper echogenic bits of tissue that can be misconstrued as teats on a female or a scrotum on a male (Stroud, 2005). However, once an ultrasound technician becomes confident with ultrasound anatomy, the scrotum and teats are helpful adjuncts to the genital tubercles when diagnosing sex. In this study were obtained results of $97 \%$ specificity, bigger than in a study from 2001 where the specificity was $83 \%$ (Tainturier, 2001). The accuracy of the procedure is determined primarily by the skill and experience level of the 
Table 2. Ultrasound diagnosis on each studied period

\begin{tabular}{ccc}
\hline & Male & Female \\
\hline 49-55 days of gestation & - & - \\
\hline 55-65 days of gestation & 7 & 5 \\
\hline 65-90 days of gestation & 14 & 9 \\
\hline 90-120 days of gestation & - & - \\
\hline Total & 21 & 14 \\
\hline
\end{tabular}

technician, quality of the ultrasound unit, and the ambient conditions during the examinations, but experienced personnel should be at least 95\% accurate in diagnosing fetal sex. In a study from 2005 the author described that since 1993 has performed more than 12,000 fetal sexing procedures with less than five reported missed diagnoses (Stroud, 2005). The diagnosis of fetal sex was established in the interval between 5590 days of gestation. Although in other studies the diagnosis was set up to 100 (Cenariu et al., 2012) and 120 days of gestation (Stroud, 2005) in our study after day 90 the diagnosis could not be established, the genital organs of fetus were not localized, the robust constitution of the mother and the migration of genital apparatus into abdominal cavity made impossible sex diagnosis at this age of gestation.

\section{Conclusions}

In mixed breed the diagnosis of fetal sexing can be set in the interval between 55-90 days of gestation. The diagnosis is made by visualizing the genital tubercle in the interval between 55-65 days of gestation and by visualizing the secondary genital organs in the interval between 65-90 days of gestation. For the correct diagnosis the technician need experience in trans-rectal exam, performant ultrasound unit and good conditions for examinations.
Acknowledgments. This research did not receive any specific grant from funding agencies in the public, commercial, or not-for-profit sectors.

\section{References}

1. Cenariu M, Pall E, Parlapan L, Groza I (2012). Ultrasonographic Determination of Fetal Sex in Cattle Bulletin UASMV, Veterinary Medicine 69(1-2), Print ISSN 1843-5262; Electronic ISSN 1843-536X 12 Number 3.

2. Des Coteaux L, Buczinski S (2009). Examen echographique de l'appareil reproducteur et de la glande mammaire [Ultrasonographic examination of the reproductive tract and mammary gland]. In: Buczinski S, Des Coteaux L, editors. Echographie des 750 Des Coteaux et al. bovins [Bovine ultrasonography]. Paris: Les Editions du Point Veterinaire; p. 109-19 [in French].

3. Des Coteaux L, Fetrow J (1998). Does it pay to use an ultrasound machine for early pregnancy diagnosis in dairy cows? In: Proceedings of the Annual Convention of the American Association of Bovine Practitioners. Spokane (WA); p. 172-4.

4. Oltenacu PA, Ferguson JD, Lednor AJ (1990). Economic evaluation of pregnancy diagnosis in dairy cattle: a decision analysis approach. J Dairy Sci;73: 2826-31.

5. Stroud BK (2005). Bovine Fetal Sexing Using Ultrasound. Proceedings, Applied Reproductive Strategies in Beef Cattle, November 12 and 13, Texas A\&M University, College Station.

6. Tainturier B (2001). Diagnostic du sexe du fœetus par echo-tomographie chez la vache. Ed. Copy Service System, Nantes, France.

7. Tyler L (2013). Fetal sex determination by ultrasonography, International Dairy Topics Volume2, number 3/ 7-9. 